\title{
The Impact of First Language Intonational Clue Selection on Second Language Comprehension
}

\author{
Leila Barati, Reza Biria \\ English Department, Islamic Azad University Khorasgan Branch, Isfahan, Iran. \\ Email: \{Leilabarati24, R_biria\}@yahoo.com \\ Received August $2^{\text {nd }}, 2011$; revised November $1^{\text {st }}, 2011$; accepted November $8^{\text {th }}, 2011$.
}

\begin{abstract}
Comprehension is closely related not only to the knowledge of words and syntax, but also the pragmatic concerns of the discourse. The purpose of the present study was to investigate the impact of the intonational clues selection of Iranian teenagers' and young adults' Persian listening comprehension ability on their English learning as a second language. According to Buck (2003), in listening comprehension the input in the form of sounds and intonational clues often conveys additional information. In this study 60 male and female teenagers (13 - 19) and 60 male and female young adults (20 - 26) were selected randomly based on Oxford Placement Test (OPT). Each group was randomly assigned to two sub groups; namely, experimental (EX) and control groups (CG), 15 participants in each group. During the study two fiction and non-fiction passages, at first in Persian and then in English, were read to participants. The passages for participants in CG were read without applying speaker's intonation changes but they were read for participants in EX with applying speaker's intonation changes. In this study factors as age and gender are important because the results showed that the difference between two groups with different age ranges was significant, and participants' inferencing, correct clue selection and listening comprehension ability in the experimental group was superior to the control group in the first language (Persian) and it also influenced positively second language learning and inferencing ability (English).
\end{abstract}

Keywords: Listening Comprehension, Intonation Clues, Inference, Pragmatic, Knowledge

\section{Introduction}

Utterance is a linguistic act in which one person expresses towards another, within a single intonation contour, a relatively coherent communicative intention in a communicative context. Intonation is used by speakers to mark the pragmatic force of the information in an utterance in spoken interaction a tone of voice, a feeling about the way our partner spoke, the atmosphere of a conversation are often more significant cues to the real message than the words themselves. They also give some syllables a greater degree of loudness and change their speech rhythm. These phenomena are called intonation. Comprehension is an active process in which a listener selects and interprets information which comes from auditory and contextual clues in order to define what is going on and what the speakers are trying to express (Rubin, 1995, 2002). Role of culture in language learning and teaching, as another factor, was investigated by Genc and Bada (2005). The study gives evidence that cultural background knowledge affects not only the comprehension scores and the recall of text propositions, but also the reading efficiency of children acquiring literacy in a first and second language. The results are most striking for comprehension scores.

In listening comprehension participants concentrate on selected aspects of aural input, form meaning from passages, and associate what they hear with existing knowledge. In making inferences learners use intra-lingual, contextual and inter-lingual clue selection. This kind of clue selection relates to the features of the new word and listeners' information about phonology, morphology, word class and collections to guess the meaning of the text or speakers' utterances. Analysis of cultural evidence should allow us to arrive at a much more accurate description, and thus understanding, of the relationship between recurrent linguistic forms and their function in discourse.

Accordingly, the learners select information from the auditory cues according to their personal knowledge and different situations for understanding the meaning of the materials read and comprehension of these materials (Hassan, 2000; Crimick \& Hill, 2001). Learners relied mostly on contextual clues when they tried to guess meanings from context. Huckin and Bloch (2002) measured the influence of contextual clues and schematic knowledge on learners ability to guess and comprehend the meaning from context.

Fiction and non-fiction passages were used to investigate if patterns existed between imaginary information and facts. Nonfiction is literature that is not fictional (Mish, 2005). However, nonfiction has a different framework Fiction texts are associated with feelings and memories, as they are a distinctive manifestation of cultural values and perceptions. Besides, they present linguistic forms, grammar, phrases, vocabulary, and formulaic speech within a meaningful and structured context that supports comprehension of the narrative world (Glazer \& Burke, 1994; Koisawalia, 2005). In fiction, a reader has to identify the characters and follow the events of the story. However, nonfiction has a different framework. In non-fiction, a listener needs to comprehend the topic, learn new facts related to it, and be able to find and remember important information (Scharer, Pinnell, \& Fountas, 2005).

Accordingly, the main purpose of this research is to investigate the impact of first language intonational clue selection on second language comprehension ability. On this basis, the following research questions are formulated:

1) Is there any relationship between Persian teenagers' and young adults' inferencing, listening comprehension and intonational clues?

2) Does first-language intonation clue selection affect second-language comprehension? 


\section{Review of the Literature}

Listening is a receptive skill in which listeners actively process information based on their schematic knowledge, as their comprehension depends on their personal experiences from the real world. Comprehension is the process of constructing the interpretation of what the text is about. Anderson \& Lynch (2003) state that one of the reasons why the listener fails to process incoming speech is that the speech contains words or phrases that the listener can hear adequately but is unable to understand because of serious problems with the syntax or semantics of the language. Gebhard (2005) points out that comprehension can only occur when the listener can place what he hears in a context. Building background knowledge and topic familiarity about context of listening texts could lead the participants to improve their listening comprehension to a significant extent during this study. As background knowledge and contextual information have important role in listening comprehension ability, Some studies have dealt with the role of contextual clues or background knowledge at the discourse level.

According to Adams (2002), presupposed knowledge and mental reference influence the listeners's inferencing of the intended meaning. According to Couper, Kuhlen and Selting (2001), a speaker's utterances are context-sensitive, it means that they are especially constructed to fit the particular location and occasion of their use. The process whereby participants construct context via such cues in order to make utterances interpretable has come to be known as contextualization (Auer \& Luzio, 2009).

Typically the supra-segmental properties guide the interpretation process while the segmental cues serve to access words in the mental lexicon. Prosodic features serve to break up the continuous utterance into clauses and phrases by the presence of pauses and boundary-marking pitch changes, and to mark one syllable or word as the focus of the speaker's attention within the accentuation prosodic cues include stress, rhythm and intonation and listeners use information about prosodic phrasing (Clark, 2008). Naturally, in spoken interaction a tone of voice, a feeling about the way our partner spoke, the atmosphere of a conversation are often more significant cues to the real message than the words themselves. They also give some syllables a greater degree of loudness and change their speech rhythm. These phenomena are called intonation. Intonation patterns often differ between languages or even between varieties of the same language. Speakers mark the pragmatic force of the information in an utterance. As a result, intonational events can often provide information to the listener about the prosodic structure, in addition to carrying a pragmatic message. Since each speaker has unique physiological characteristics of speech production and speaking style, speaker-specific characteristics are also reflected in prosody. Speaker-specific prosody and idiosyncrasies that are recognized by the listener, either consciously or otherwise (Fujio, 2007). June (2005) classifies Persian with English, German, Dutch, Greek, Italian, Spanish, Portuguese, Arabic, and Bininj Gun-wok as "stress-accent" languages, i.e., languages in which a certain syllable in a word is more prominent than other syllables by phonetic factors, showing syntagmatic contrast. Pitch accents in Persian occur on the lexically stressed syllables (Eslami \& Bijankhan, 2003). In this regard, some works have been done on Persian intonation, which include Eslami (2003) and Mahjani (2003). The smallest intonational unit in Persian is the accentual phrase (AP) with the pitch accent $\mathrm{L}+\mathrm{H}^{*}$ associating with the stressed syllable.

\section{Methodology}

It is used by speakers to mark the pragmatic force of the information in an utterance. As a result, intonational events can often provide information to the listener about the prosodic structure, in addition to carrying a pragmatic message. In spoken interaction a tone of voice, a feeling about the way speaker spoke, the atmosphere' of a conversation often give significant cues to different age groups of listeners for inferencing. According to Keene and Zimmerman (1997), inferring is going beyond the literal text for weaving utterance into our mind as a meaningful communication.

This study investigates how correct intonation clues selection from both fiction and non-fiction passages in speaker's utterance has influence on two age ranges of teenagers and young adults' Persian inferencing as their first language and the influence of that on English inferencing as their second language. The participants included 60 male and female teenagers and 60 male and female young adults. The age range for the teenagers and young adults were chosen from 13 - 19 and 20 - 26 age ranges respectively. Teenagers and young adults have different mental experiences and background knowledge and accordingly have different inference from fiction and non-fiction passages. For example, teenagers inferences are more based on real world facts than personal experiences while young adults inferences are more related to their background knowledge and experiences.

All participants were native speakers of Farsi that were learning English as a second language. The samples were randomly chosen from 100 male and female teenagers and 100 male and female young adults studying in an English Language Center in Iran. The students who after Oxford Placement Test (OPT), toke scores between 15 to 18 participate in this study were divided in two groups of Control Group (CG) and Experimental Group (EX). The situation for both group were the same and only the materials for testing their comprehension were different. During the study two fiction and non-fiction passages were read aloud without intonational changes to participants in CG. Then, the same passages were read with intonational changes to participants in EX and they were asked some questions about the passages.

The materials for testing participants' inferencing and evaluating their second language listening comprehension ability of making schematic references consisted of two fiction and two non-fiction passages (one in Persian and one in English) that were read aloud to participants. The passages were created according to Leslie Holzhauser-Peters, M.S., CCC-SLP, and author. The passages were no more than 150 words. Each passage was submitted to The Lexiles (2008) Framework ${ }^{1}$ for Reading and Listening which matches the appropriate grade level to each text. Each text was given a lexile score, which indicated what grade level, corresponded with each passage.

By the way, responses were recorded verbatim. In Table 1, participants were given comprehension scores according to their logical thinking, clue selection and mental inferencing from zero to four based on Lexile’s score:

\section{Results}

After participant, according to OPT, were randomly chosen,

${ }^{1}$ This is a framework for reading and listening which matches the appropriate score to each text based on degree of difficulty of text and each text was given a Lexile score from zero to four. 
Table 1.

Explanation of participants' inference/logical thinking of the passages.

\begin{tabular}{cl}
\hline Lexile's Score & \multicolumn{1}{c}{ Participant's inferencing and clue selection } \\
\hline 4 & $\begin{array}{l}\text { Participants make logical inference and mental thinking } \\
\text { most of the time }\end{array}$ \\
3 & $\begin{array}{l}\text { Participants make logical inference and mental thinking } \\
\text { some of the time }\end{array}$ \\
2 & $\begin{array}{l}\text { Participants don't make logical inference and mental } \\
\text { thinking some of the time }\end{array}$ \\
1 & $\begin{array}{l}\text { Participants don't make logical inference and mental } \\
\text { thinking most of the time }\end{array}$ \\
0 & Participants didn't attempt to guess or explain \\
\hline
\end{tabular}

during the study and then two fiction and non-fiction passages were read aloud to both gender (male and female) and age (teenagers and young adults) participants in CG and Ex, then, learners responses to speakers question about the passages were recorded verbatim. The Tables 2 and 3 show the statistical results of this study.

As Tables 2 and 3 indicate, the greatest mean score $(\mathrm{M}=$ 3.53) belonged to the comprehension of non-fiction passages in the experimental group and the lowest mean score (2.21) belonged to the comprehension of non-fiction in the control group. Ability in the experimental group is greater than for the control group.

According to Tables 4 and 5, the greatest mean score $(\mathrm{M}=$ 3.75 ) belonged to the comprehension of fiction passages in the experimental group and the lowest mean score (2) belonged to the comprehension of fiction in CG. So, as these tables show, second language learners in EX have listening comprehension ability than control group. The following Tables (6-9) show the impact of intonation on two age groups of teenagers and young adults from second language listening comprehension ability of fiction and non-fiction passages.

Comparing Tables 6-9 indicate that the greatest mean score ( $\mathrm{M}=3.63$ ) belonged to the young adults comprehension of non-fiction passages in the experimental group and the lowest mean score (2.66) belonged to the young adults comprehension of non-fiction in the control group. In general, as tables statistically describe, age as a variable influenced second language listening comprehension ability in experimental group more than control group. Statistical analysis of this study are presented in the Table 10.

As Tables 10 and 11 demonstrates, gender as a variable had meaningful impact on the listening comprehending ability. Significant level of this variable on the first and second language listening comprehension (Respectively, .003 and .013) was less than .05 . It means that there is significant difference between male and females listening comprehension ability of Persian and English.

Also according to these two tables, both their native language and their second language intonation clues make a significant difference and the impact of the added experience that being older provides also was significant.

\section{Discussion and Conclusions}

According to findings of this study, the investigations are in agreement with some previous researches pointing to the importance of listening comprehension ability on the development of inference ability such as Wagner (2006).
Table 2.

First language listening comprehension test without considering intonation changes.

\begin{tabular}{cccccc}
\hline $\mathrm{N}$ & Minimum & \multicolumn{2}{c}{ Maximum } & Mean & Std. Deviation \\
\hline Fiction & 60 & .00 & 4.00 & 2.8667 & .87269 \\
Non-Fiction & 60 & .00 & 4.00 & 2.2167 & .86537 \\
Valid N (listwise) & 60 & & & & \\
\hline
\end{tabular}

Table 3.

First language listening comprehension with considering intonation changes.

\begin{tabular}{cccccc}
\hline $\mathrm{N}$ & Minimum & Maximum & Mean & Std. Deviation \\
\hline Fiction & 60 & 2.00 & 4.00 & 3.2500 & .60014 \\
Non-Fiction & 60 & 2.00 & 4.00 & 3.5333 & .68064 \\
Valid N (listwise) & 60 & & & & \\
\hline
\end{tabular}

Table 4.

Second language listening comprehension test without considering intonation changes.

\begin{tabular}{cccccc}
\hline $\mathrm{N}$ & Minimum & Maximum & Mean & Std.Deviation \\
\hline Fiction & 30 & .00 & 4.00 & 2.0033 & .935 \\
Non-Fiction & 30 & 2.00 & 4.00 & 2.1667 & .592 \\
Valid N (listwise) & 30 & & & & \\
\hline
\end{tabular}

Table 5.

Second language listening comprehension test with considering intonation changes.

\begin{tabular}{cccccc}
\hline $\mathrm{N}$ & Minimum & Maximum & Mean & Std. Deviation \\
\hline Fiction & 30 & 2.00 & 4.00 & 3.7500 & .004 \\
Non-Fiction & 30 & .00 & 4.00 & 3.4667 & .006 \\
Valid N (listwise) & 30 & & & & \\
\hline
\end{tabular}

Table 6.

Teenagers second language listening comprehension test without considering intonation changes.

\begin{tabular}{cccccc}
\hline $\mathrm{N}$ & Minimum & Maximum & Mean & Std. Deviation \\
\hline Fiction & 30 & .00 & 4.00 & 2.7000 & 1.02217 \\
Non-Fiction & 30 & .00 & 4.00 & 2.7667 & .89763 \\
Valid N (listwise) & 30 & & & & \\
\hline
\end{tabular}

Table 7.

Young adults second language listening comprehension test without considering intonation changes.

\begin{tabular}{cccccc}
\hline $\mathrm{N}$ & Minimum & Maximum & Mean & Std.Deviation \\
\hline Fiction & 30 & 2.00 & 4.00 & 3.0333 & .66868 \\
Non-Fiction & 30 & .00 & 4.00 & 2.6667 & .84418 \\
Valid N (listwse) & 30 & & & & \\
\hline
\end{tabular}


Table 8 .

Teenagers second language listening comprehension test with considering intonation changes.

\begin{tabular}{cccccc}
\hline $\mathrm{N}$ & Minimum & \multicolumn{2}{c}{ Maximum } & Mean & Std. Deviation \\
\hline Fiction & 30 & 2.00 & 4.00 & 3.1333 & .57135 \\
Non-Fiction & 30 & 2.00 & 4.00 & 3.0333 & .71840 \\
Valid N (listwise) & 30 & & & & \\
\hline
\end{tabular}

Table 9.

Young adults second language listening comprehension test with considering intonation changes.

\begin{tabular}{cccccc}
\hline $\mathrm{N}$ & Minimum & \multicolumn{2}{c}{ Maximum } & Mean & Std. Deviation \\
\hline Fiction & 30 & 2.00 & 4.00 & 3.3667 & .61495 \\
Non-Fiction & 30 & 3.00 & 4.00 & 3.6333 & .49013 \\
Valid N (listwise) & 30 & & & & \\
\hline
\end{tabular}

Table 10.

The significant result of first language listening comprehension test.

\begin{tabular}{cccccc}
\hline Source & $\begin{array}{c}\text { Type III } \\
\text { Sum } \\
\text { of Squares }\end{array}$ & df & Mean Square & F & Sig. \\
\hline Intercept & 2220.417 & 1 & 2220.417 & 4005.728 & .000 \\
Gender & .017 & 1 & .017 & .030 & .003 \\
Age & 4.267 & 1 & 4.267 & 7.697 & .006 \\
Intonation & 15.000 & 1 & 15.000 & 27.061 & .000 \\
Error & 63.300 & 116 & .554 & & \\
\hline
\end{tabular}

Table 11.

The significant result of second language listening comprehension test.

\begin{tabular}{cccccc}
\hline Source & $\begin{array}{c}\text { Type III } \\
\text { Sum } \\
\text { of Squares }\end{array}$ & df & Mean Square & F & Sig. \\
\hline Intercept & 2220.417 & 1 & 2220.417 & 4005.728 & .000 \\
Gender & .017 & 1 & .017 & .030 & .013 \\
Age & 4.267 & 1 & 4.267 & 7.697 & .008 \\
Intonation & 15.000 & 1 & 15.000 & 27.061 & .001 \\
Error & 64.300 & 116 & .554 & & \\
\hline
\end{tabular}

Leslie and Caldwell (2000) found evidence that skilled learners have higher levels of prior knowledge and understood and comprehended the text better and more accurately than poorer. Since listening comprehension needs some previous information and personal experience, the listeners of both languages (Persian and English) who make mental inference by means of background knowledge are more successful in this ability. In fact, background knowledge and personal experience based on cultural and social features is individually different. The results of this study indicate that teenagers in both groups and gender inference based on their personal experiences while young adults inferencing of texts are based on the real world and facts.

Duke (2000) defined informational context as what had a function to communicate information about the natural or social world, an expectation of durable factual information, timeless verb construction, generic noun construction, technical vocabulary, definitional material, compare/contrast, problem/solution, cause/effect, or similar text structures, frequent repetitions of the topical theme and graphical elements such as diagrams, indices, page numbers, and maps.

In this study fiction and non-fiction passages were used to investigate if patterns existed between imaginary information and learners' inference of real facts. As fiction texts are associated with feelings and are distinctive manifestation of cultural values and perceptions, in this study fiction passages were chosen as part of the overall texts. When learners listen to fiction passage, as mental states are central in narrative texts, can use mental reference and emotional features to make personal inference.

On the other hands, non-fiction has a different framework. In non-fiction, a reader or listener needs to comprehend the topic, learn new facts related to it, and be able to find and remember important information (Scharer, Pinnell, Lyons, \& Fountas, 2005).

Boynton and Blevins (2004) emphasized the fact that listening and understanding nonfiction text demands abstract thinking. They accessed, comprehend, and integrated related concepts and ideas. According to Wagner (2006), results indicated that students' clue selection, logical thinking abilities, and overall inferential thinking abilities were more developed in fiction passages than nonfiction passages. Also according to the discriptive results of the present study, females comprehension of fiction passages is more than males. In the other words, males comprehension of non-fiction passages in this study is more than females.

Besides, Richards \& Anderson (2003) believe that inferencing is a strategic process in comprehension which one generates assumptions, makes predictions, and comes to conclusions based on the given information. So, linguistic information in the form of speech and written text is ultimately essential for making inferences and associations between text information and knowledge about the world.

The schema is the mental map or set of mental connections in mind about a particular idea of thing (Myhill, Jones, \& Hopper, 2006). Studies investigated that schematic knowledge facilitates comprehension and helps listeners deal with barriers in communication. Therefore, in order to inferencing take place and lead to meaningful comprehension, making schematic interpretation needed. As a result, when listeners cannot generate inferences, they fail to comprehend with implied information in other parts of the passage.

Buck (2003), Lynch and Mevald (2009), believe that speech is linear and encoded in the form of sound with the presence of a rich prosody (stress, intonation, rhythm, loudness and more) which is absent from the written language.

According to Hassan (2000) listener selects information from the auditory cues according to personal knowledge. Therefore, in listening comprehension process, the phonological information are the first things that listener receives from speakers speech and matches them with his mental information and identifies, interprets and comprehends meaning of the words or phrases he listened to. Learners as the first step of listening comprehension identifies sound signals according to speakers' utterances and selects intonational clues of the overall context.

Listening comprehension involves interaction with a speaker and requires prior experience of a listener to interpret what the speaker says (Jeo, 2007). According to Buck (2001), listening 
involves both linguistic and non-linguistic knowledge. It means that, linguistic knowledge relates to knowledge of phonology, lexis, syntax, semantics, discourse structure, pragmatics and sociolinguistics, whereas non-linguistic refers to knowledge of the topic, the context and general knowledge about the world and how it works.

According to the present study, background knowledge had an important role in using mental schematic references to inference and make comprehension. Different cognitive and social factors as personal experience, mental schematic, culture, gender, age and etc. influence inferencing skill.

According to the results of this study, when speaker (Both Persian and English languages) does not apply intonational counters in the utterance and speakers prosodic knowledge is inadequate, inferencing will not be made correctly and comprehension will be weak or incorrect. On the other hand, when learner is not familiar with the prosodic system and contextual features of the language the attention-focusing mechanism will not be employed and as a result comprehension cannot correctly be made.

By rising and lowering the pitch of the voices change degree of loudness and speech rhythm speakers can express different emotion by means of intonational cues. The significant gains of the experimental group in this study stated that considering intonational clues in the speakers utterance had positive impact on listeners comprehension. For the experimental group, the pitch of the voice raised and lowered to form pitch patterns as intonnational clues of utterance. Each intonation clue as a prosodic characteristic in speech reveals some important information regarding the identity of the spoken language.

Present study concluded that considering intonational changes, age and gender factors in speakers utterance, influenced correct inferencing and comprehension ability. In this study, when these factors implied on Persian students, who were learning English as a second language, the results showed that those students who select intonational clues of the first language correctly for comprehending passages were those English learners who had the most Lexiles scores of inferencing and comprehension ability. According to the results of this study and previous researches, future studies can investigate the influence of another factors on inference and comprehension ability such as culture, society and economy.

\section{Acknowledgements}

I have had great fortune during this studies. I would like to express my special appreciation to Dr. Reza Biria whose invaluable suggestions and constructive comments helped me in accomplishing this study. Finally I would like to thank all of the students and teachers who took part in the experiment.

\section{References}

Adams, M. (2002). Teaching English. Journal of English Linguistics, 30, 353-365. doi:10.1177/007542402237883

Anderson, K., \& Lynch, T. (1998). Listening. Oxford: Oxford University Press.

Anderson, K., \& Lynch, T. (2003). Learner/non-teacher interact the contribution of a course assistant to EAP speaking classes. Interaction and Language Learning. TESOL Case Studies in Practice Series. Alexandria, VA: TESOL.

Auer, P., \& Luzio, A. D. (2009). The contextualization of language. A Methodological Paradigm Discussion. Oxford: Oxford University Press.
Bachman, L. (1990). Fundamental considerations in language testing. Oxford: Oxford University Press.

Boynton, A., \& Blevins, W. (2004). Teaching students to read nonfiction. New York: Scholastic Professional Books.

Buck, G. (2001). Assessing listening. Cambridge: Cambridge University Press.

Buck, G. (2003). Establishing annual measurable objectives for LEP students' English language proficiency. Paper presented at the National Title Directors' Conference, Annaheim.

Chen, Z. (2009). Language models for contextual error detection and correction, all 13 versions. CLAGI 09 Proceedings of the EACL. Stroudsburg.

Clark, B. (2008). The effects of intonation in discourse: The semantics and pragmatics of focus. Past Colloquia Organized by Janet Pierrehum, Northwestern University.

Couper-Kuhlen, E., \& Selting, M. (2001). Interactional linguistics. Studies in Discourse and Grammar, Amsterdam: Benjamins.

Duke, N., \& Bennett-Armistead, V. (2003). Reading and writing informational text in the primary grades: Research-based practices. New York: Scholastic.

Eslami, M., \& Bijankhan, M. (2003). Persian intonation system. Iranian Journal of Linguistics, 34, 36-61.

Fujio, M. (2007). Communication strategies for the negotiation, establishment, and confirmation of common ground: A longitudinal study of Japanese-British conversational interaction. Unpublished Doctoral Thesis. Tokyo: The University of Tokyo.

Gebhard, M. (2005). Hybrid discourses, and second language literacy and culture faculty. TESOL Quarterly, 39, 187. doi:10.2307/3588308

Genc, B., \& Bada, E. (2005). Culture in language learning and teaching. The Reading Matrix, 5, 73-84.

Glazer, S., \& Burke, M. (1994). An integrated approach to early literacy. Australian Review of Applied Linguistics, 15, 95-106.

Grasser, A., Gernsbacher, R., \& Goldman, R. (2003). Theories of social cognition. Learning Technology Center, University of WisconsinMadison.

Hansen, J. (2000). Inferential comprehension strategy for use with primary grade children. The Reading Teacher, 34, 665-669.

Hoek, K., \& Kibrik, A. (2000). Discourse studies in cognitive linguistics: Selected papers from the fifth international cognitive linguistics conference, Amsterdam: J. Benjamins.

Huckin, T., \& Bloch, J. (2002). Strategies for inferring word meanings in context: A cognitive model. In T. Huckin, M. Haynes and J. Coady (Eds.), Second Language Reading and Vocabulary Learning (pp. 153-178). Norwood: Ablex Publishing Corporation.

Hui, C. (2005). Pragmatic inference based on model [J]. The complementary of cognitive linguistics and relevance theory. Washington: University of Washington.

Jeo, H. (2007). A phonetic study on phrasing. The 2nd European Conference on Korean Linguistics, 88-101

June, F. (2005). Discourse and computational linguistics. Michigan: Michigan University Press.

Keene, E., \& Zimmerman, S. (1997). Mosaic of thought: Teaching comprehension in a reader's workshop. Portsmouth, NH: University Massachusetts Press.

Kintsch, W. (1998). Comprehension: A paradigm for cognition. Cambridge, MA: Cambridge University Press.

Leslie, L., \& Caldwell, J. (2009). Social linguistics and litercies Ideology in discourses, Formal and informal measures of reading. Princeton, NJ: Princeton University.

Lexile (2008). Lexile framework for reading. URL (last checked 5 March 2006) http://www.lexile.com

Mahjani, B. (2003). An instrumental study of prosodic features and intonation in modern farsi (persian) supervisor: Robert Ladd Master of Science. Edinburgh: University of Edinburgh.

McCormick, S., \& Hill, D. S. (2001). An analysis of the effects of tow procedures for increasing disabled readers inferencing skills. Journal of Educational Research, 77, 219-226.

Mewald, C., Gassner, O., \& Siggott, G. (2009). Testing listening specifications for the E8-standards listening tests. LTC Technical Report. http://www.uni-klu.ac.at/ltc/downloads/LTC_Technical_Report

Mils, K. (2005). Deconstructing binary oppositions in literacy discourse and pedagogy. Journal of Language and Literacy, 28, 67-82.

Mish, F. (2005). Merriam-Webster's collegiate dictionary. (11th ed.). 
Springfield, MA: Merriam-Webster, Inc.

Myhill, D., Jones, S., \& Hopper, R.(2006). Talking, listening and learning: Effective talk in the primary classroom. Maidenhead: Open University Press.

Oka, H., \& Fujio, M. (2005). How do strategies work? Invest gating practical English ability. Bulletin of the Foreign Language Teaching Association, 9, 1-21.

O’Malley, J. (1996). Authentic assessment for language learners. Reading, MA: Addison-Wesley.

Richards, J. C., \& Anderson, N. A. (2005). How do you know? A strategy to help emergent readers make inferences. The Reading Teacher, 57, 290-293.

Scharer, P., Pinnell, S., Lyons, C., \& Fountas, I. (2005). Becoming an engaged reader. Educational Leadership, 63, 24-29. http://www.ascd.org/portal/site/ascd/menuitem.a4db
Vandergrift, L. (2004). Listening to learn or learning to listen. Annual Review of Applied Linguistics, 24, 3-25.

Van Dijk, T. A. (2008). Discourse and context. A sociocognitive approach. Cambridge: Cambridge University Press. doi:10.1017/CBO9780511481499

Van, O. H., \& Goldman, R. (1999). Text and context in functional linguistics. The construction of mental representations. Washington DC: National Academy Press.

Wagner, D. T. (2006). How knowledge helps. http://www.aft.org/pubs-reports/american_educator/issues/sprin

Watson, K., \& Smeltzer, R. (2000). Different categories about listening comprehension facts: Comparison between students and practitioners. Communication Research Reports, 1, 82-87.

Xie, X. (2005). The influence of schema theory on foreign language reading comprehension. The English Teacher, 34, 65-75. 